\title{
Measuring inefficiency in the Norwegian bus industry using multi-directional efficiency analysis
}

Holvad, Torben; Hougaard, Jens Leth; Kronborg, Dorte; Kvist, Hans Kurt

Document Version

Final published version

Publication date:

2002

License

CC BY-NC-ND

Citation for published version (APA):

Holvad, T., Hougaard, J. L., Kronborg, D., \& Kvist, H. K. (2002). Measuring inefficiency in the Norwegian bus industry using multi-directional efficiency analysis.

Link to publication in CBS Research Portal

\footnotetext{
General rights

Copyright and moral rights for the publications made accessible in the public portal are retained by the authors and/or other copyright owners and it is a condition of accessing publications that users recognise and abide by the legal requirements associated with these rights.

Take down policy

If you believe that this document breaches copyright please contact us (research.lib@cbs.dk) providing details, and we will remove access to the work immediately and investigate your claim.
}

Download date: 26. Apr. 2023 


\title{
Measuring Inefficiency in the Norwegian Bus Industry using Multi-directional Efficiency Analysis
}

\author{
Torben Holvad \\ Transport Studies Unit \\ University of Oxford
}

Jens Leth Hougaard*

Institute of Economics

University of Copenhagen

\author{
Dorte Kronborg \& Hans Kurt Kvist \\ Department of Statistics \\ Copenhagen Business School
}

\section{REVISED VERSION}

\begin{abstract}
This paper deals with methods of measuring and analyzing efficiency in transport industry. The aim of the paper is to introduce and demonstrate the advantages of Multi-directional Efficiency Analysis (MEA) in case of cost data with limited substitution possibilities. For this purpose we reconsider the Norwegian bus data that has previously been analyzed using econometric models and Data Envelopment Analysis; Jørgensen, Pedersen and Solvoll (1995), Jørgensen, Pedersen and Volden (1997) and Odeck and Alkadi (2001). It is shown how, using MEA, it becomes possible to disaggregate inefficiency into different components corresponding to different types of cost generating variables and thereby provide both managers of the bus companies and policy makers with more detailed information on possible improvements of performance.
\end{abstract}

\footnotetext{
*Corresponding author: Institute of Economics, University of Copenhagen, Studiestraede 6, 1455 Copenhagen K., Denmark. E-mail: Jens.Leth.Hougaard@econ.ku.dk
} 
Keywords: Inefficiency measurement, MEA, Bus industry, Transport.

Acknowledgements: The authors wish to thank Finn Jørgensen and Gisle Solvoll for kindly providing the data set and information about the Norwegian bus industry and the anonymous referees of this journal for their many helpful comments. 


\section{Introduction}

There is by now a considerable literature on the measurement of efficiency in bus industries. In particular, recent European studies have considered the British (Cowie and Asenova 1999) and the Norwegian (Jørgensen et al. 1995, Jørgensen et al. 1997, and Odeck and Alkadi 2001) bus industry using parametric as well as non-parametric methods to estimate the levels of technical efficiency - see e.g. Berechman (1993) or De Borger et al. (2000) for a review of these methods. Moreover, the performance of the Swedish and Spanish bus industry has been analyzed in Hulten and Folster (1998) and De Rus and Nombela (1997) respectively. The primary interest seems to have been to investigate the effects of ownership, company size, geographical location etc. on the efficiency assessments. Once such effects are clarified there are of course immediate implications for company management and transport policy.

In the present paper we intend to reconsider the Norwegian bus data. Previously, Jørgensen, Pedersen and Solvoll (1995), have studied the cost structure of the Norwegian bus companies using a modified Cobb-Douglas function. Jørgensen, Pedersen and Volden (1997) use a stochastic frontier model to estimate the inefficiency of bus operations and disclose an average saving potential for the Norwegian bus companies between $14 \%$ and $7 \%$ depending upon the underlying assumptions. Finally, Odeck and Alkadi (2001) use Data Envelopment Analysis (DEA) to estimate the level of efficiency with results showing an average saving potential of around $28 \%$ (with a slightly different data set).

For analysis of the Norwegian bus data we apply yet another method to estimate the levels of inefficiency; the so-called Multi-directional Efficiency Analysis (MEA), see Bogetoft and Hougaard (1999 and 2002) and Asmild et al. (2003). MEA, like DEA, is a non-parametric method, differing from DEA in the way in which efficiency is measured. In other words, MEA makes use of an entirely different efficiency index. We shall argue that MEA is better suited for dealing with technologies exhibiting limited substitution possibilities (in inputs) as in the present model of bus companies. Moreover, in general MEA has the advantage that from a managerial viewpoint, it provides more relevant performance information (in a sense to be made precise in the following) and it allows for a more substantive analysis of the effect of external variables on the inefficiency scores.

Throughout the paper we shall compare our results with the results ob- 
tained from previous studies of the Norwegian bus industry. In short, we find considerable improvement potentials that are even larger than those estimated by Odeck and Alkadi. In addition to the results in Odeck and Alkadi, we are able to relate specific improvement potentials to the specific input dimensions and reveal that DEA seems to overestimate the savings potential in fuel costs, whereas, for example, it underestimates the savings potential in costs that are not related to fuel or driver utilization. Further analysis on the influence of external factors indicate that public companies have a better utilization of fuel than private companies. Given fuel costs, on the other hand, private companies have a better utilization of drivers than public companies. Subsidy allocation policies have no effect on the utilization of fuel and drivers. There is, though, an effect on other costs in the sense that ceteris paribus companies with negotiated subsidies are less efficient than companies with subsidies based on cost norms. Such effects cannot be analyzed using a single efficiency score as in e.g. DEA.

The paper is organized as follows: Section 2 provides a further motivation for the paper. Section 3 presents the data set and basic input-output model to be used, and a preliminary investigation of the data is performed. Section 4 presents the general methodology. The potential improvements idea is introduced and the programmes of Multi-directional Efficiency Analysis (MEA) are stated. Section 5 presents the results of MEA and uses the related results from DEA for comparison. Section 6 goes on to further investigate the results and the findings are compared to the results obtained from the previous studies of the Norwegian bus data in Section 7.

\section{Motivation}

As mentioned in the introduction, previous studies of the Norwegian bus industry have used different techniques and obtained surprisingly different results even taking into account that different data sets were used. The most recent study in Odeck and Alkadi (2001) is the one disclosing the worst state of performance, with an average saving potential of $28 \%$ using the DEA technique to assess levels of inefficiency. In general, we agree that some form of non-parametric analysis is preferable when assessing cost efficiency of bus companies. However, the particular choice of DEA is unfortunate in this case as we shall presently explain.

Since the bus companies are subsidized and their route frequency is partly 
predetermined it seems natural to consider aspects of cost efficiency, that is, to focus on the ability of the bus services to operate efficiently measured in terms of costs per output (in the present study, seat kilometers, defined in Section 3). In other words, the underlying production process related to bus services is described by a number of cost generating inputs (fx. fuel and personnel) and output. For such production technologies one should indeed expect to find rather limited substitution possibilities between cost driving inputs; buses are worth nothing without drivers, fuel is worth nothing without buses etc. Indeed, it seems that technologies representing the performance of different types of transport units are likely to resemble so-called Leontief technologies.

It is well known that DEA with its use of the Farrell efficiency index performs badly when the technology is characterized by limited substitution possibilities (see e.g. Färe, Grosskopf and Lovell 1993). The problem is simply that dominated companies may appear as efficient and that a relatively large part of the sample will be measured against such dominated benchmark units - this seems to call for the use of another type of efficiency index that only refers to undominated benchmark units. Moreover, contrary to the previous studies of the Norwegian bus data that have focused on the overall performance of the bus industry, we focus on analyzing managerial performance by estimating the improvement potential in each input dimension taken separately for each company - again this seems to call for more attention related to the benchmark selection process.

In the DEA literature there are several tricks in order to avoid that inefficient companies are assigned maximum performance score or that companies in general are compared to dominated benchmarks. Technically, the Farrell index may be generalized such that reference to undominated benchmarks is ensured, for example, using the Russell index (see e.g. Färe, Grosskopf and Lovell 1993). Loosely speaking, the implicit selection of benchmarks (because it is actually an implicit selection correspondence) related to the Russell index, for a given company, is determined by minimizing a linear function with gradient equal to the inverse of the company's input usage over the set of dominating production plans (see also Section 4 for further details). Thus, as an implicit selection procedure the Russell index does not ensure unique selection and the selection it ensures is determined by past production in a one dimensional sense, just as in case of the Farrell index, only this time in the dual space (as fixed pseudo prices). Moreover, as an efficiency index the value is practically without economic interpretation and therefore void 
of managerial information.

Now, a more direct approach is taken in Bogetoft and Hougaard (1999, 2003), where it is suggested to focus on the benchmark selection procedure and then, as a second order issue, to consider the measurement of inefficiency. In short, the idea is to analyse the improvement potentials in each input (or output) dimension separately for each company in the sample. Instead of considering improvements in proportion to past production, as in DEA, or relative to the cost minimizer given pseudo-prices determined by past production, as in case of the Russell index, it seems more natural to consider improvement potential in proportion to the input specific saving potentials: Some companies may have limited possibilities to save on some inputs while they have considerable possibilities to save on others. A benchmark selection based on potential improvements is always undominated, and in Bogetoft and Hougaard (op cit.), it is demonstrated that its axiomatic foundation is indeed more attractive than the foundation of the implicit Farrell benchmark selection as used in DEA. In the present paper we shall use the benchmark selection based on potential improvements and estimate the improvement potentials (or excesses) in each input dimension for each bus company. The specific approach that we apply has been named Multi-directional Efficiency Analysis (MEA) in Asmild et al. (2003).

To disclose input specific improvement potentials is of course an advantage from a purely managerial point of view as it immediately indicates the specific dimensions where performance has to be improved. In fact, as we shall demonstrate empirically, there may be huge differences in the utilization of different inputs for the same company. Furthermore, the input specific information also turns out to provide a much better foundation for subsequent analyses of the influence of external factors. To be more specific, the results can be analysed using multivariate analysis of the relative improvement potentials and that provides the opportunity to consider the managerial implications with respect to various unmodelled issues - possibilities that are somewhat limited using e.g. DEA or econometric approaches. We shall demonstrate that compared to the information from DEA, the MEA approach provides additional insights with respect to 'characterizations' of efficient companies and thereby better indications for various transport policy issues, such as the importance of ownership, competitive pressure, and contract design. 


\section{Cost efficiency model and data description}

Data have been provided from official reports from 175 subsidized Norwegian bus companies to the county councils for the 1991 calendar year. The complete database covers all 175 bus companies but 21 companies had to be discarded due to extreme observations or missing data for key variables to be used as inputs. Four companies appeared to have reported inaccurate data. Six other companies were considered to operate in incomparable conditions with reference to the other companies in the database (for example, one of these is the main bus operator in Oslo, another is a small company with very low costs because some routes are served by hired taxi cabs). Data for 11 companies could not be used in the analysis due to missing information on costs. Except from the county Buskerud, each of the 17 remaining Norwegian counties are represented in the data set and most counties have a number of entries in the database (the only exception is Finnmark County, the county furthest to the North with only a single bus company). The company size in the data set varies considerably; if number of seat kilometers is used as an indicator of size then the smallest company achieves approximately 460,800 seat kilometers, the largest company provides 620.5 mill seat kilometers, while the average bus company provides 93 mill seat kilometers.

To model the productive activities undertaken by the bus companies we use the following cost variables as inputs:

Inputs: Fuel costs, Driver costs and Other costs.

All inputs are measured in Norwegian Kroner (NOK). The variable Other costs includes remaining costs items (including depreciation).

For each company Seat kilometers is calculated as the total number of vehicle kilometers times the average bus size (sum of seating capacity and standing places). Consequently, Seat kilometers captures the aspect of differences in bus size and is chosen as a proxy for output:

Output: Seat kilometers.

Descriptive statistics for 154 companies are given for the input and output variables in Table 1. A common feature is that the distributions are highly skewed to the right and very large variations are present. This is due to large variations between companies in both number of busses and kilometers. 


\begin{tabular}{|l|rrrrr|}
\hline Variable & Mean & Median & Min & Max & Std.dev. \\
\hline Fuel & $1,571,908$ & 84,730 & 16,151 & $9,775,000$ & $1,902,667$ \\
Driver & $9,392,579$ & $4,198,948$ & 64,000 & $72,129,317$ & $12,889,105$ \\
Other & $12,344,193$ & $6,724,687$ & 113,646 & $96,070,696$ & $15,987,531$ \\
Seat kms. & $93,092,799$ & $48,267,000$ & 460,800 & $620,418,190$ & $117,407,247$ \\
\hline
\end{tabular}

Table 1. Descriptive statistics for in- and output variables.

On the basis of the available information, it is possible to examine the extent to which inefficiency can be explained by certain characteristics which may be of importance in shaping performance of bus companies. Besides geographical information on the area where the companies operate, the following information may be used:

* Whether the bus company is engaged in sea transport (10\%) or not $(90 \%)$.

* Whether the bus company operates in a coastal area $(53 \%)$ or not (47\%).

* Whether the bus company is privately (77\%) or publicly owned $(23 \%)$.

* Whether the method of subsidy allocation includes the ability to negotiate the size of the subsidy $(49 \%)$ or is based entirely on cost norms $(51 \%){ }^{1}$

The majority of bus companies are not engaged in sea transport. Moreover, the majority of subsidized bus companies are privately owned and a slight majority of the companies received subsidy from the county based on cost norms.

\subsection{A first look at the data}

The first impression of the data set is that companies with low input costs have low values of Seat kilometers, and vice versa. Moreover, low costs in one input-dimension is typically followed by low costs in the other input

\footnotetext{
${ }^{1}$ Contracts between bus companies and county councils are generally based on cost norms but some companies have the ability to negotiate with the councils over the size of the subsidy.
} 
dimensions as well, and the variation increases with increasing company size. In other words, the data points lie within a narrow convex cone indicating that bus services can be described by an underlying technology with constant returns to scale (CRS).

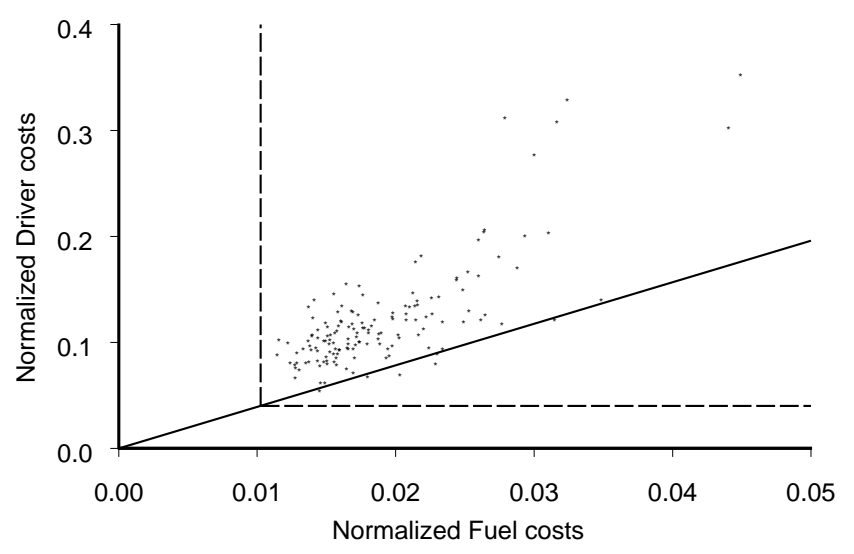

Figure 1: Normalized Fuel costs versus normalized Driver costs.

If we restrict attention only to fuel and driver costs this picture becomes even clearer as it can be expected that very limited substitution possibilities between fuel and driver inputs are present. In Figure 1, using the assumption of constant returns to scale, we have normalized the inputs by the output variable Seat kilometers and hence obtained a given isoquant. Indeed, it appears that only one observation is undominated and hence determines the frontier of the input possibility set. In other words, the isoquant is a Leontief isoquant (with no substitution between inputs). Further analysis show that 
the extreme inefficient companies are all small, whereas among the more efficient companies all sizes are present.

Adding the third input variable Other costs will only result in a slightly changed performance picture, as we shall see in Section 5, despite the fact that Other costs involves a number of different cost items with possible larger variation between the companies. Consequently, by introducing the input variable Other costs we also introduce substitution possibilities although they remain limited.

For further analysis of the cost data it seems straightforward to apply methods like Data Envelopment Analysis (DEA, see e.g. Charnes et al. 1994) to measure the efficiency of each bus company, as done in Odeck and Alkadi (2001) for example. However, as mentioned in Section 2, it is well known that the standard version of DEA uses the radial Farrell index of technical efficiency which has the drawback that it may implicitly relate to dominated benchmark units. In the worst case this implies that index value 1 (indicating best performance) may be assigned to companies that are actually dominated in one or more inputs (or outputs). Unfortunately this problem is particularly critical in our case, as the underlying technology of the bus companies closely resembles a Leontief technology where inputs cannot be substituted. It is easy to get an idea of the problem by looking at Figure 1 above where any bus company that is not located on the ray from the origin through the point determined by the undominated company (solid line in Figure 1) is implicitly compared to benchmarks on the vertical or horizontal segment of the isoquant (dashed lines in Figure 1). In fact, all inefficient observations in Figure 1 are compared to either the vertical or the horizontal part of the frontier and thereby compared to dominated benchmarks.

As mentioned in Section 2, we suggest to apply Multi-directional Efficiency Analysis (or MEA) in order to analyse cost efficiency of the Norwe-

gian bus companies. Hence, the following section will briefly review this procedure.

\section{Methodology: Multi-directional Efficiency Analysis}

Before the linear programming problems involved in the calculation of the inefficiency scores using Multi-directional Efficiency Analysis (MEA-scores) 
are stated, it is necessary to define the potential improvements benchmark selection and the related efficiency index. For terms of reference, the potential improvements approach will be compared to the implicit benchmark selection of the Farrell and Russell efficiency index.

To provide some intuition consider Figure 2, where $x=\left(x_{1}, x_{2}\right)$ is the input combination of a given company and $\mathrm{L}$ is the

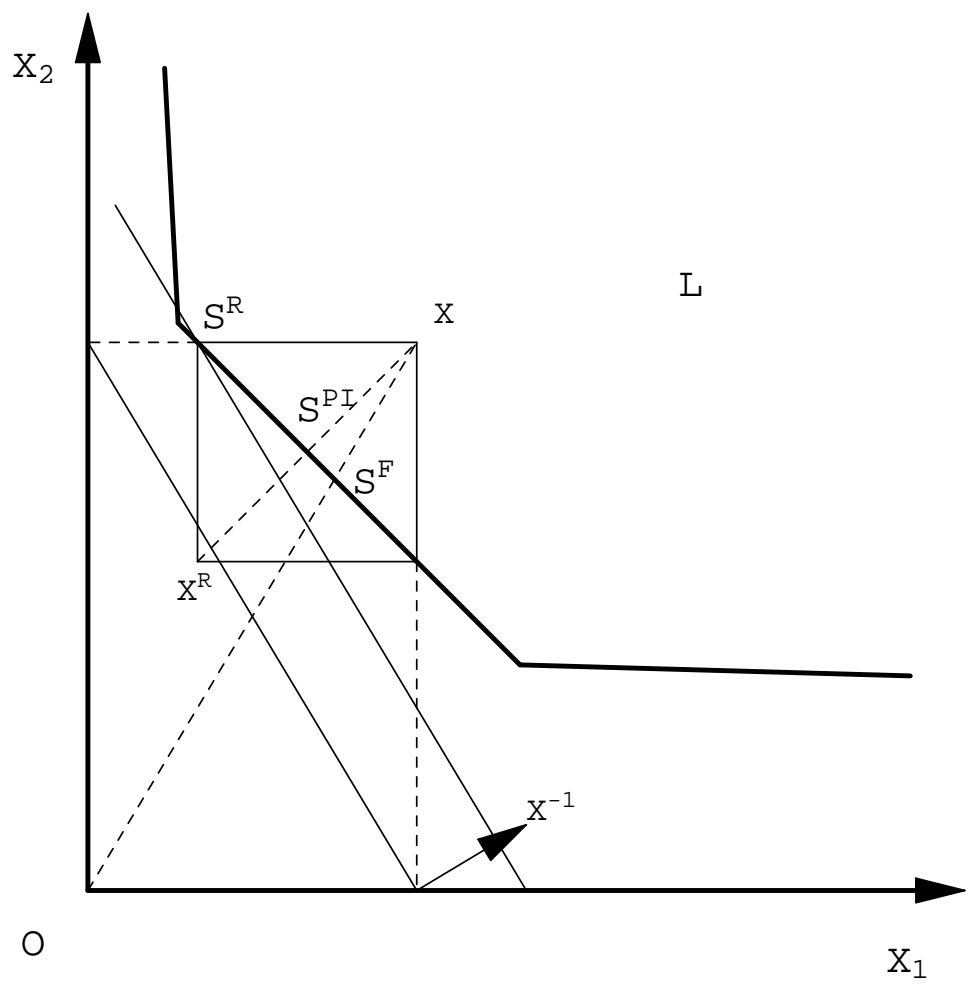

Figure 2: Illustration of the MEA procedure.

production possibility set determined by convex data envelopment.

Using Farrell's index of technical efficiency where the implicit benchmark is found in proportion to past production $x$, the plan $S^{F}$ is selected. Using the Russell index, where benchmarks are those production plans (in this particular case the unique plan) that minimize a linear function with gradient $1 / x$ 
over the set of undominated production plans, the implicit selection becomes $S^{R}$. Finally, using the potential improvements approach the benchmark $S^{P I}$ is selected relative to the input specific improvement potentials.

Thus, in general $S^{P I}$ is determined in the following way: Relative to $x \in$ $\mathbf{R}_{+}^{m}$ the ideal production $x^{R}(x) \in \mathbf{R}_{+}^{m}$ is determined by $x^{R}(x)=\left(x_{i}^{R}(x)\right)_{i=1}^{m}$ where $x_{i}^{R}(x)=\min \left\{x_{i}^{\prime} \in \mathbf{R} \mid\left(x_{1}, \ldots, x_{i}^{\prime}, \ldots, x_{m}\right) \in L\right\}$ and $L$ is the input requirement set - that is, $x^{R}$ is found as the full input reduction potential in each input dimension taken separately. The benchmark selection $S^{P I}$ is found as the largest possible reduction of $x$ in the direction of the ideal production $x^{R}$, that is, in proportion to the input specific excesses $x_{i}-x_{i}^{R}$.

Comparing the three approaches based on Figure 2 we see that the Farrell selection neglects the huge (both absolute and relative) improvement potential in input 1 since by definition we are forced to consider only reductions proportional to the actual production. In the extreme opposit case the Russell selection completely disregards the improvement potential in input 2 , although this is also significant. The potential improvements selection, on the other hand, ensures that the selected benchmark reflects the size of the individual improvement potentials by considering reductions in proportion to these. For a general analysis of the merrits of the potential improvements approach the reader is referred to Bogetoft and Hougaard (1999), Hougaard and Tvede (2002) and Asmild et al. (2003).

Now, the potential improvements inefficiency index $E^{P I}$ is then determined as the (possibly weighted) ${ }^{2}$ average of the excesses relative to benchmark $S^{P I}$ in each input dimension $i$, i.e., as the average of $x_{i}-S_{i}^{P I}$ for all $i$. Therefore efficient companies get index value (MEA-score) 0, whereas inefficient companies get scores larger than 0 and increasing with increasing inefficiency; see Bogetoft and Hougaard (1999) for further theoretical details.

Let a set of $n$ decision making units, DMUs, $(j=1, \ldots, n)$ produce $s$ outputs $y_{r}(r=1, \ldots, s)$ using $m$ inputs $x_{i}(i=1, \ldots, m)$. Consider the production plan $\left(x^{k}, y^{k}\right)$ of $\mathrm{DMU}_{k}$. To calculate the value of the potential improvements inefficiency index for $\mathrm{DMU}_{k}$, the ideal reference point $x^{R}\left(x^{k}\right)$ is found by solving $m$ linear programming problems (one for each input dimension):

$$
\min _{\lambda, \theta_{i}} \theta_{i} \quad \text { s.t. }
$$

\footnotetext{
${ }^{2}$ Weights may be exogeneously determined by the analyst but in the present study we use a simple average.
} 
$\sum_{j=1}^{n} \lambda^{j} x_{i}^{j} \leq \theta_{i}$

$\begin{array}{lc}\sum_{j=1}^{n} \lambda^{j} x_{-i}^{j} \leq x_{-i}^{k}, & -i=1, \ldots, i-1, i+1, \ldots, m \\ \sum_{j=1}^{n} \lambda^{j} y_{r}^{j} \geq y_{r}^{k}, & r=1, \ldots, s\end{array}$

for $\lambda \geq 0$ or $\lambda \in\left\{\lambda \geq 0 \mid \sum_{j} \lambda^{j}=1\right\}$

assuming constant or variable returns to scale respectively.

Letting $\left(\lambda^{*}, \theta_{i *}\right)$ solve the above problems for $i=1, \ldots, m$, the ideal point is given by $x^{R}\left(x^{k}\right)=\left(\theta_{1 *}, \ldots, \theta_{m *}\right)$. If $x^{R}\left(x^{k}\right)=\left(\theta_{1 *}, \ldots, \theta_{m *}\right)=x^{k}$ we know that $\mathrm{DMU}_{k}$ is (input) efficient and consequently $E^{N P I}\left(x^{k}\right)=0$. Hence, assume that $x^{R}\left(x^{k}\right) \neq x^{k}$ and consider the following linear programming problem:

$$
\begin{array}{ll}
\max _{\lambda, \beta} \beta \quad \text { s.t. } & \\
\sum_{j=1}^{n} \lambda^{j} x_{i}^{j} \leq x_{i}^{k}-\beta\left(x_{i}^{k}-x_{i}^{R}\left(x^{k}\right)\right), & i=1, \ldots, m \\
\sum_{j=1}^{n} \lambda^{j} y_{r}^{j} \geq y_{r}^{k}, & r=1, \ldots, s \\
\text { for } \lambda \geq 0 \text { or } \lambda \in\left\{\lambda \geq 0 \mid \sum_{j} \lambda^{j}=1\right\} . &
\end{array}
$$

The solution $\left(\lambda^{* *}, \beta^{*}\right)$ to this program can be used to determine both the benchmark selection $S^{P I}$ and the index value $E^{P I}$ as follows:

$$
S^{P I}\left(x^{k}\right)=x^{k}-\beta^{*}\left(x^{k}-x^{R}\left(x^{k}\right)\right)
$$

and

$$
E^{P I}\left(x^{k}\right)=\sum_{i=1}^{m}\left(x_{i}^{k}-S_{i}^{P I}\left(x^{k}\right)\right)=\beta^{*} \sum_{i=1}^{m}\left(x_{i}^{k}-x_{i}^{R}\left(x^{k}\right)\right),
$$

where excesses in all dimensions are considered equally important (otherwise a weighted sum could have been used). Note that since all input variables are measured on the same monetary scale (in NOK) the value of $E^{P I}$ directly indicates the monetary loss connected with being inefficient. In the following we shall also consider the relative improvement potential both in general and with respect to the individual inputs, i.e.,

$$
\frac{E^{P I}\left(x^{k}\right)}{x^{k}}=\frac{\beta^{*} \sum_{i=1}^{m}\left(x_{i}^{k}-x_{i}^{R}\left(x^{k}\right)\right)}{x^{k}}
$$

and

$$
\frac{\beta^{*}\left(x_{i}^{k}-x_{i}^{R}\left(x^{k}\right)\right)}{x_{i}^{k}}, \forall i
$$


Note, that in the case where there are no substitution possibilities in inputs, i.e. when the isoquants are Leontief isoquants, the value of the Russell index is identical to (one minus) the average of the relative input specific improvement potentials. This however, is not the case when substitution possibilities are introduced as in our three input model in Section 5 below.

Now, one way to compare the potential improvements index with the Farrell index,

$$
F(x)=\min \{t \in \mathbf{R} \mid t x \in L\}, x \in L,
$$

on the premisses of the first, is to use the implicit Farrell selection $S^{F}=$ $F(x) x$ instead of $S^{P I}$ in the definition of $E^{P I}$. A Farrell inefficiency index may hence be defined as,

$$
E^{F}(x)=\sum_{i=1}^{m}\left(x_{i}-S_{i}^{F}\right)=(1-F(x)) \sum_{i=1}^{m} x_{i} .
$$

Clearly, $E^{F}(x) \geq 0$ and its value increases as $x$ gets more inefficient.

Below, we shall refer to values of the index $E^{P I}$, calculated using the above programmes, as $M E A$-scores for each observation in the data set. Likewise we shall refer to values $E^{F}$ as $D E A$-scores.

\section{Results and comparison with DEA}

Initially, the input-output model described in Section 3 is analysed assuming a constant returns to scale technology. The main focus will be on results obtained by analysis of the MEA scores, but DEA-scores will be used for comparison. In an attempt to study the influence of the variable Other costs on the measure of inefficiency, a model with only Fuel costs and Driver costs is analysed in addition to a model including all three input variables. 


\begin{tabular}{|l|rrr|rrr|}
\hline \multirow{2}{*}{} & \multicolumn{6}{|c|}{ MEA, CRS. Only inefficient companies } \\
& \multicolumn{7}{|c|}{ Model with three inputs } \\
& Absolute excess (NOK) & Relative excess (\%) \\
\hline Variable & Mean & Min. & Max. & Mean & Min. & Max. \\
\hline Fuel & 387,359 & 8,024 & $2.762,840$ & 29.3 & 6.66 & 68.6 \\
Driver & $3,441,167$ & 31,977 & $35,235,119$ & 38.6 & 2.19 & 78.3 \\
Other & $5,239,511$ & 39,472 & $49,295,492$ & 43.2 & 2.08 & 77.9 \\
\hline MEA scores & $9,068,039$ & 95,705 & $82,843,537$ & 40.8 & 2.73 & 76.3 \\
\hline & \multicolumn{6}{|c|}{ Model with two inputs } \\
& Absolute excess (NOK) & Relative excess (\%) \\
\hline Variable & Mean & Min. & Max. & Mean & Min. & Max. \\
\hline Fuel & 620,996 & 10,304 & $3,878,981$ & 44.4 & 15.4 & 77.5 \\
Driver & $5,683,112$ & 41,061 & $50,569,252$ & 60.7 & 16.9 & 88.4 \\
\hline MEA scores & $6,304,108$ & 51,365 & $53,000,937$ & 58.5 & 20.6 & 87.1 \\
\hline
\end{tabular}

Table 2. MEA results under CRS.

In the sample of 154 bus companies only one (0.6\%) turns out to be fully efficient in the two-input model as shown in Figure 1 above, whereas three companies $(1.9 \%)$ become fully efficient if the third input variable is added and the full model is considered. In Table 2 the size of the input specific excesses $\left(x_{i}-S_{i}^{P I}\right)$ are summarized. Only inefficient companies are included. Considering the three-input model the average excess is around 9 mill. NOK, out of which 5.2 mill. NOK originates from excess in Other costs, 3.4 mill. NOK from Driver costs and an average excess of 0.4 mill. NOK is from Fuel costs. The immediate observation is that there are large potentials for cost saving in all inputs. But the absolute saving potentials are, of course, largest for Other costs and Driver costs, as they constitute the main cost categories. Considering the relative potentials for costs saving (Table 2), the saving potentials are of almost equal magnitude. Still, the largest saving can be obtained for Other costs. Both for the absolute and the relative saving, large variations between companies are present. 


\begin{tabular}{|l|rrr|rrr|}
\hline \multirow{2}{*}{} & \multicolumn{5}{|c|}{ MEA, VRS. Only inefficient companies } \\
& \multicolumn{5}{|c|}{ Model with three inputs } \\
& Absolute excess (NOK) & Relative excess (\%) \\
\hline Variable & Mean & \multicolumn{1}{c|}{ Min. } & Max. & Mean & Min. & Max. \\
\hline Fuel & 357,546 & 831 & $2,660,524$ & 27.2 & 1.01 & 55.4 \\
Driver & $2,606,390$ & 6,868 & $13,993,339$ & 35.7 & 1.66 & 70.7 \\
Other & $3,910,512$ & 5,199 & $28,321,401$ & 35.8 & 1.59 & 73.9 \\
\hline MEA scores & $6,874,448$ & 23,863 & $41,448,926$ & 35.8 & 2.26 & 70.1 \\
\hline
\end{tabular}

Table 3. MEA results under VRS.

Comparing the model with only two inputs (Fuel costs and Driver costs) with the three input model, the mean potential improvements becomes larger when Other costs are disregarded. The relative saving increases; for the mean relative saving this increase is $52 \%$ for Fuel costs and $57 \%$ for Driver costs.

Consider MEA scores under the assumption of variable returns to scale (VRS). In the model with three inputs the number of fully efficient companies increases to 15 (9.7\%). Further, as a consequence of the variable returns to scale assumption, the distances from the observations to the frontier of the estimated production possibility set becomes smaller, which is reflected in a decrease in all mean excesses as seen in Table 3. Potential improvements are still largest for variables Other costs and Driver costs both absolute and relative. Notice that the potential improvement for variable Other costs is relatively speaking reduced the most compared to the constant returns to scale scenario. This is mainly due to the fact that substitution possibilities (although limited) are introduced by the variable Other costs.

The standard DEA model uses Farrell's radial efficiency score and hence implicitly a benchmark found as the intersection between the ray from the origin and the frontier of the production possibility set. To compare MEA and DEA we may interpret the DEA efficiency scores along the lines of the MEA methodology by accessing the absolute excesses relative to the DEA 


\begin{tabular}{|l|rrr|rrr|}
\hline \multirow{2}{*}{} & \multicolumn{6}{|c|}{ DEA, CRS. Only inefficient companies } \\
& \multicolumn{7}{|c|}{ Model with three inputs } \\
& Absolute excess (NOK) & Relative excess (\%) \\
\hline Variable & Mean & Min. & Max. & Mean & Min. & Max. \\
\hline Fuel & 529,780 & 7,458 & $3,114,769$ & 37.3 & 2.48 & 74.7 \\
Driver & $3,146,246$ & 37,345 & $21,735,231$ & 37.3 & 2.48 & 74.7 \\
Other & $4,257,531$ & 41,556 & $29,035,148$ & 37.3 & 2.48 & 74.7 \\
\hline DEA scores & $7,933,557$ & 86,360 & $53,191,933$ & 37.3 & 2.48 & 74.7 \\
\hline & \multicolumn{6}{|c|}{ DEA, VRS. Only inefficient companies } \\
& \multicolumn{7}{|c|}{ Model with three inputs } \\
& Absolute excess (NOK) & Relative excess (\%) \\
\hline Variable & Mean & Min. & Max. & Mean & Min. & Max. \\
\hline Fuel & 379,202 & 1,073 & $2,260,199$ & 30.9 & 1.62 & 63.8 \\
Driver & $2,154,572$ & 6,674 & $12,802,299$ & 30.9 & 1.62 & 63.8 \\
Other & $3,036,868$ & 7,390 & $16,985,531$ & 30.9 & 1.62 & 63.8 \\
\hline DEA scores & $5,570,642$ & 15,447 & $29,211,851$ & 30.9 & 1.62 & 63.8 \\
\hline
\end{tabular}

Table 4. DEA results under $C R S$ and VRS.

selected benchmark unit as described in Section 4. These results are given in Table 4 for both constant and variable returns to scale. The overall total excess is seen to be smaller than the excess obtained using MEA. That is, in general DEA underestimates the reduction potential with around 1 mill. NOK on average, corresponding to $13 \%$ for constant and $19 \%$ for variable returns to scale.

Looking at specific inputs this picture becomes somewhat more complex. The mean of the excess obtained from Fuel costs by DEA are 36.7\% larger than the mean excess obtained from MEA. Furthermore, assuming constant returns to scale technology the mean excess obtained from Driver costs by DEA is $8.5 \%$ smaller than the corresponding excess from MEA while the excess obtained from Other costs is $18.7 \%$ smaller than the MEA excess. A similar tendency is seen if a variable returns to scale technology is assumed. Notice that in the standard version of DEA it is assumed that the relative excesses are independent of input direction. In our case the calculated mean of the relative excesses is $37.3 \%$ in the constant returns to scale case and $30.9 \%$ in the variable returns to scale case. 

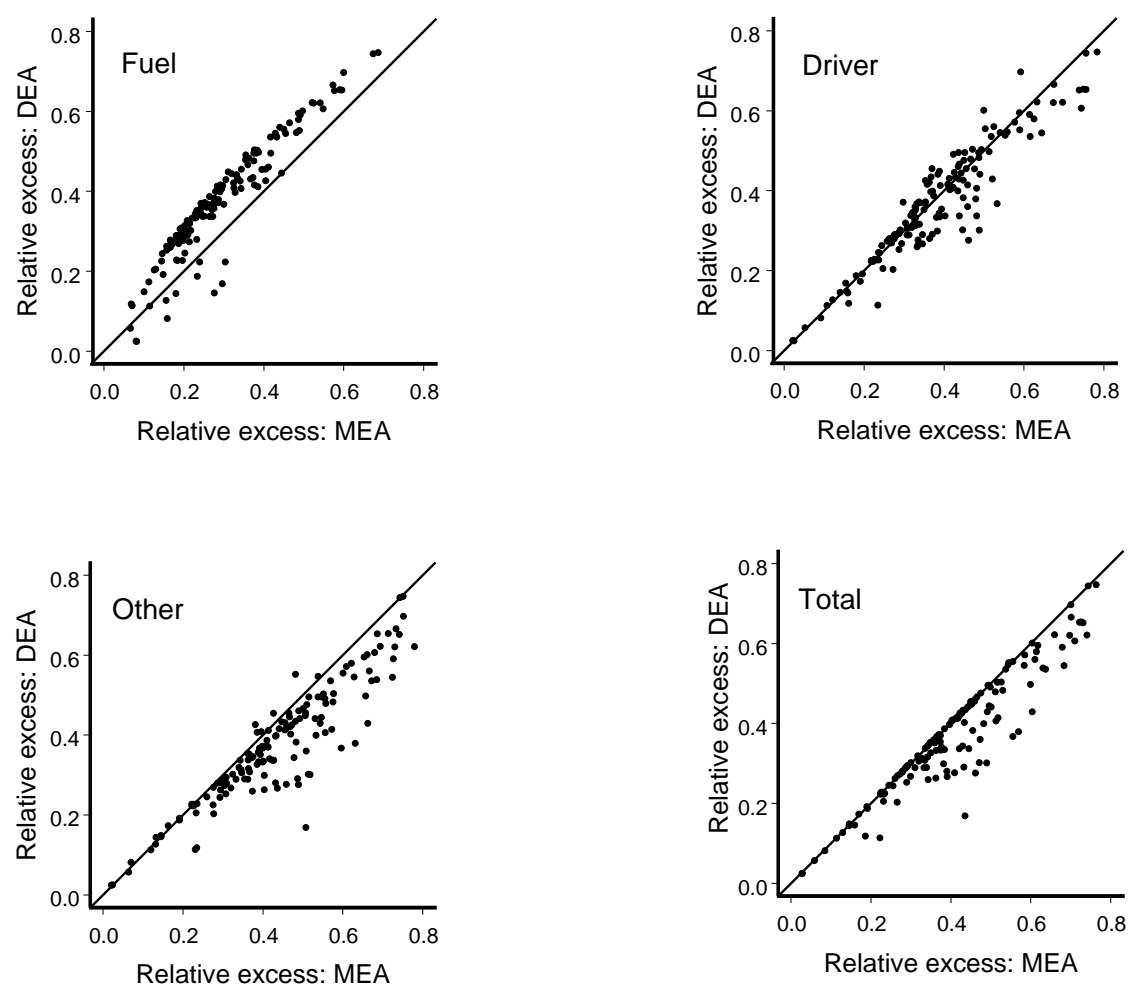

Figure 3: Relative DEA and MEA excesses against each other for each input variable and the total costs under CRS. Model with three inputs.

Considering the company specific excesses (Figure 3), the above mentioned differences between DEA and MEA excesses are generally speaking re-discovered. For Fuel costs almost all companies have larger relative DEA excess than MEA excess, whereas the opposite tendency is present for Other costs. The input variable Driver costs displays a somewhat mixed picture, with some companies having the largest relative excess with respect to MEA and others with respect to DEA. In other words, DEA overestimates the reduction potential in Fuel costs and underestimates the reduction potential in Other costs. In total, we find that DEA underestimates the reduction potential, as $69 \%$ of the companies have larger relative excesses in MEA than in DEA with a maximal difference of $27 \%$. A closer inspection of the total 


\begin{tabular}{|l|l|rrr|}
\hline Company & Method & Fuel costs & Driver costs & Other costs \\
\hline Unit no. 15 & DEA & 0.17 & 0.17 & 0.17 \\
& MEA & 0.30 & 0.15 & 0.51 \\
\hline Unit no. 115 & DEA & 0.38 & 0.38 & 0.38 \\
& MEA & 0.29 & 0.48 & 0.63 \\
\hline
\end{tabular}

Table 5. Relative DEA and MEA excesses for two specific companies under $C R S$.

relative excesses demonstrates, though, that $52 \%$ of the companies differs less than $1 \%$ in the relative potential saving between MEA and DEA.

To emphasize the difference between relative DEA excesses and relative MEA excesses on a company level, consider Table 5. Here the values for two specific companies are shown. The relative DEA excesses are the same (by definition) while the relative MEA scores vary extensively, and clearly differ significantly from the DEA excesses.

To sum up on the difference between MEA and DEA: First, since MEA only relates to undominated benchmark units, the overall tendency is that MEA discloses more improvement potential than DEA, as demonstrated in Tables 2,3,4, and 5 and Figure 3. Second, the use of the Farrell index in DEA forces the relative improvement potentials to be identical for all inputs, as seen in Table 4 and 5. Thus, we do not get any impression of differences in the utilization of the various inputs. MEA, on the other hand, provides such a performance picture, where some inputs are revealed as having a larger improvement potential than others, cf. Table 5 . In this specific case we saw that DEA had a tendency of overestimating the reduction potential in Fuel costs, but underestimate the reduction potential in Other costs, as seen in Figure 3. From a purely managerial point of view, this information is highly relevant, since it suggests where to improve performance for the individual companies: Some companies may find large improvement potentials in Driver costs, others in Fuel, and so on. Furthermore, the input specific information also has implications for further analysis of the efficiency result, as we shall demonstrate in Section 6 below. 


\section{Some managerial implications of unmod- elled issues}

As mentioned above, MEA scores provide the possibility for a more subtle analysis of different impacts of external factors with respect to the individual cost variables. This will be demonstrated by comparison with a similar kind of analysis using DEA scores for the three input model with constant returns to scale.

For analyzing the influence of the external factors on the saving potentials, the following variables are available, as described in Section 3: County; Coastal area, that is whether or not the bus company operates in coastal area; Sea transport, that is whether or not the company is engaged in sea transport; Ownership, that is private or public companies; and Subsidy allocation, that is whether this is based on negotiations or cost norms. The variable Coastal area is coarser than the variable County and it could be appropriate to include nested effects, but due to the relatively limited number of companies compared to number of external variables included, it has not been possible to further distinguish between counties. Thus, only the coarser variable Coastal area is used to describe geographical variations. Furthermore, since almost all companies engaged in sea transport are private companies operating in coastal areas, an eventual effect of being involved in sea transport must be analysed within this subgroup.

To assess the influence of the external factors on the relative MEA excesses, analyses were performed in each input direction separately. Since the relative MEA excesses are highly correlated with all three correlations being roughly 0.9 , the marginal analyses were supplemented with a multivariate analysis of variance (MANOVA) (e.g., Rao (1965 or later), Johnson \& Wichern (1992)). Here the relative excesses are considered as a multivariate response rather than as a collection of univariate responses. This may provide additional information in cases where the marginal responses are dependent. Moreover, the conditional distribution of each input variable given one or both of the others are analysed. Both marginal analyses, conditional analyses, and multivariate analyses performed subsequently depend to some extent on normality within subgroups defined by the external variables and combinations hereof. But even though the relative excesses, both in MEA and in DEA, are bounded between zero and one, closer inspection of the distribution of the data including analysis of the residuals reveals that 
the assumption of normality is not unreasonable. Moreover, as only three companies are fully efficient the classical problem with several observations with zero excess vanishes. Ordinary $\mathrm{F}$ or t tests are used for marginal and conditional analyses, and since the number of degrees of freedom is large, $\mathrm{F}$ test approximations to Wilks lambda are used in evaluation of significance when performing MANOVA.

Analyzing the relative MEA excesses in the three-dimensional normal distribution model (MANOVA) it turns out that an interaction term between Coastal area and Subsidy allocation has weak but significant influence on the mean $(\mathrm{F}(3,144))=2.96, \mathrm{p}=0.4 \%)$, and that the effect of Ownership is significant $(\mathrm{F}(3,144)=4.57, \mathrm{p}=0.4 \%)$.

It is well-known that using MANOVA significant effects can occur even if an external variable influences nothing but one of the dependent variables. A more comprehensive investigation of the effects, therefore, was performed. First, marginal analyses shows a particulary simple model for relative excess in Fuel costs, that depends only on Ownership and Coastal area.

Analysing the conditional distributions given relative excess in Fuel costs it was found that only Ownership had a significant effect on relative excess in Driver costs. Continuing this successive conditioning only Subsidy allocation were found to affect the relative excess in Other costs.

The analysis performed then results in the following structural equations, as giving a fairly good description of the data.

$$
\begin{aligned}
& \mu_{R O E}=\alpha_{\text {Other }}+\beta_{1} R F E+\gamma R D E+\delta_{\text {Subsidy allocation }}, \\
& \mu_{R D E}=\alpha_{\text {Driver }}+\beta_{2} R F E+\nu_{\text {Ownership }} \\
& \mu_{R F E}=\alpha_{\text {Fuel }}+\xi_{\text {Ownership }}+\eta_{\text {Coastal area }}
\end{aligned}
$$

where $\mu$ 's are conditional mean values for the relative MEA excesses of Fuel (RFE), Driver (RDE), and Other (ROE) costs respectively. Regarding the estimated effects, companies operating in coastal areas have higher potential for saving in Fuel costs than non-coastal companies. The estimated difference is $\hat{\eta}_{\text {Coastal area }}=0.0996$ (SE: 0.0195 ) meaning that the potential saving is 9.96 percentage points larger for companies operating in coastal areas. Furthermore, private companies have higher $\left(\hat{\xi}_{\text {Ownership }}=6.49 \%(\mathrm{SE}: 2.28 \%)\right)$ potential for saving in Fuel cost than public companies. Controlling for relative excess in Fuel cost, the effect of ownership on Driver costs was that public companies have larger $\left(\hat{\nu}_{\text {Ownership }}=3.98 \%\right.$ (SE:1.34\%)) saving potential than private companies. Finally, the effect of Subsidy allocation policy 
on the relative excess in Other costs, given the relative excess in both Driver and Fuel costs, was that companies with subsidy allocation based on negotiations had larger $\left(\hat{\delta}_{\text {Subsidy allocation }}=2.92 \%(\mathrm{SE}: 0.90 \%)\right)$ potential for relative saving than those with subsidy allocation based on cost norms.

Concerning private companies operating in coastal areas, the relative potential saving in Driver cost is $5.6 \%$ (SE: $0.23 \%$ ) lower for those not engaged in sea transport than for companies engaged in sea transport.

Considering the relative DEA excesses, the result of performing an ordinary analysis of variance (or multiple regression analysis) shows that only the variable Coastal area has significant influence on the saving potential $(\mathrm{t}(149)=4.9, \mathrm{p} \leq 0.00 \%)$. The estimated difference is $0.108(\mathrm{SE}=0.022)$, meaning that the relative potential saving for companies operating in coastal areas are in mean 0.108 (10.8\%) larger than for those not operating in coastal areas.

\section{Discussion}

While Odeck and Alkadi (2001) draw no specific conclusions with respect to possible managerial and policy implications, Jørgensen et al. (1995), using almost the same data set as ours but a traditional econometric model, obtain results that in general are in accordance with our findings. They estimate that companies operating in coastal areas have $10 \%$ higher costs than elsewhere, and that bus companies engaged in sea transport have $16 \%$ higher costs than those not engaged in sea transport. Moreover, subsidy allocation policies influence total costs such that the cost reduction when changing policy from negotiations to cost norms reduces with $20 \%$ for public companies and $12 \%$ for private companies.

However, using MEA we can say more than that: we find that the about 10 percentage points of possible saving for companies operating in coastal areas are primarily related to inefficient utilization of the Fuel input, as is the 6.5 percentage points saving for private companies. Fixing the Fuel costs, potential savings in Driver costs were found to be about 4 percentage points larger for public than for private companies. And finally, among companies with comparable Fuel and Driver costs, those with subsidy allocation based on negotiations had almost 3 percentage point larger saving potential. For policy makers this information is useful as it identifies more precisely the 
possible contribution which introduction of cost norms can achieve in terms of improved cost efficiency.

Jørgensen et al. (1995) find it remarkable that companies engaged in sea transport were found to have $16 \%$ higher costs than the others. In the MEA analysis, controlling for Fuel costs, the difference in saving potentials between those engaged and those not engaged in sea transport is estimated to only 5.7 $\%$ for Driver costs. Moreover, engagement in sea transport was not found to relate to saving marginally in neither Fuel costs nor Other costs, given Fuel and Driver costs. This is probably a more realistic result suggesting that diseconomies of scope are less important

In a later paper, Jørgensen et al. (1997) use stochastic frontier models. Here the response variable is total cost per vehicle-kilometer. The obtained inefficiencies are subsequently analyzed for influence of the external variables and they find that neither ownership nor subsidy policy influence inefficiency. The obtained results were found to be dependent on the choice of error distribution and consequently only weak conclusions are stated. However, their result is in accordance with the present results, where the potential for savings was found only to depend on whether or not the company operates in coastal areas.

\section{References}

Asmild, M., J.L. Hougaard, D. Kronborg \& H.K. Kvist (2003). Measuring Inefficiency Via Potential Improvements, Journal of Productivity Analysis, 19, 59-76.

Berechman, J. (1993). Public Transit Economics and Deregulation Policy, North-Holland.

Bogetoft, P. \& J.L. Hougaard (1999). Efficiency Evaluations Based on Potential (Non-proportional) Improvements, Journal of Productivity Analysis, 12, 231-245.

Bogetoft, P. \& J.L. Hougaard (2003). Super Efficiency Based on Potential Slack, European Journal of Operational Research, to appear.

Cowie, J. \& D. Asenova (1999). Organisation Form, Scale Effects and Efficiency in the British Bus Industry, Transportation, 26, 231-248. 
De Borger, B., K. Kerstens \& A. Costa (2000). Public Transit Performance: What Does one Learn from Frontier Studies, Transport Reviews, 22, $1-38$.

De Rus, G. \& G. Nombela (1997). Privatisation of Urban Bus Services in Spain, Journal of Transport Economics and Policy, 31, 115-129.

Farrell, M.J. (1957). The Measurement of Productive Efficiency. Journal of the Royal Statistical Society, Series A, III, 253-290.

Färe, R., S. Grosskopf \& C.A.K. Lovell (1993): Production Frontiers, Cambridge University Press.

Hougaard J.L. \& M. Tvede (2002): Benchmark selection: An axiomatic approach; European Journal of Operational Research, 137, 218-228.

Hulten, S. \& S. Folster (1998). The Effects of Competition in Swedish Local Bus Services, Journal of Transport Economics and Policy, 32, 203-219.

Johnson, R.A. \& D.W. Wichern (1992). Applied Multivariate Statistical Analysis, Prentice-Hall.

Jørgensen, F., P.A. Pedersen \& G. Solvoll (1995). The Costs of Bus Operations in Norway, Journal of Transport Economics and Policy, 29, 3, 253-262.

Jørgensen, F., P.A. Pedersen \& R. Volden (1997). Estimating the Inefficiency in the Norwegian Bus Industry from Stochastic Cost Frontier Models, Transportation, 24, 421-433.

Odeck, J. \& A. Alkadi (2001). Evaluating Efficiency in the Norwegian Bus Industry Using Data Envelopment Analysis, Transportation, 28, 211232.

Rao, C.R. (1964). Linear Statistical Inference and Its Applications, Wiley. 